\title{
Emissions from Petrol Engine Fueled Gasoline-Ethanol-Methanol (GEM) Ternary mixture as Alternative Fuel
}

\author{
Saravana Kannan Thangavelu ${ }^{1,2, a}$, Piraiarasi Chelladorai ${ }^{1, b}$, and Farid Nasir $\mathrm{Ani}^{2, \mathrm{c}}$ \\ ${ }^{1}$ Faculty of Engineering, Computing and Science, Swinburne University of Technology, Kuching, Sarawak, Malaysia \\ ${ }^{2}$ Faculty of Mechanical Engineering, Universiti Teknologi Malaysia, Skudai, Johor D.T., Malaysia
}

\begin{abstract}
The increasing demands of petroleum fuels due to the rapid development automotive society coupled with the environmental pollution issues have inspired the efforts on exploring alternative fuels for internal combustion engines. Bioethanol obtained from biomass and bioenergy crops has been proclaimed as one of the feasible alternative to gasoline. In this study, the effect of gasoline-ethanol-methanol (GEM) ternary blend on the emission characteristics of petrol engine was studied. Three different fuel blends, namely, E0 (gasoline), G75E21M4 (75\% gasoline, 21\% hydrous ethanol and 4\% methanol) and E25 (25\% anhydrous ethanol and 75\% gasoline) were tested in a 1.3-1 K3-VE spark-ignition engine. The results indicate that, when G75E21M4 fuel blend was used, a significant drop in $\mathrm{CO}, \mathrm{CO} 2, \mathrm{NOx}$ and $\mathrm{HC}$ emissions by about $42 \%, 15 \%, 7 \%$ and $5.2 \%$ compared to E0, respectively. Moreover, the emission results for G75E21M4 are marginally lower than E25 whereas; HC emission was slightly higher than E25.
\end{abstract}

\section{Introduction}

The increasing demands of petroleum fuels together with the greenhouse gas emission have stimulated the efforts on discovering new alternative fuels. The most significant alternative for replacing petroleum fuels are biofuels (bioethanol). Many researches have investigated the effect of ethanol and gasoline blends in petrol engines. More than 95\% researchers noticed that the carbon monoxide (CO) and hydrocarbon (HC) emissions significantly decreased, whereas oxides of nitrogen (NOx) and carbon dioxide $(\mathrm{CO} 2)$ emissions were not significant. Thus, there is impending research needs to achieve significant reduction in $\mathrm{NOx}$ and $\mathrm{CO} 2$ emissions for bioethanol fuel blend. In bioethanol fuel production from lignocellulosic biomass, while using the normal column type distillation, a maximum of $96 \%$ ethanol was obtained with $3.7 \%$ methanol from the fermented bioethanol in our previous study [1]. A high energy and cost is required to separate the methanol from bioethanol after distillation. This ternary mixture of lignocellulosic bioethanol can be used in the SI engine. Turner et al. [2] recommend using ethanol-methanol-gasoline ternary blend to flexi-fuel vehicles after examining the isostoichiometric properties of ternary blends (85\% ethanolmethanol content rate). Elfasakhany [3] investigated the effect of ethanol-methanol-gasoline ternary blends in single cylinder SI engine at lower content rate of ethanolmethanol blend (3-10 Vol. \%). Moreover, Sileghem et al. [4] studied the effect of ethanol-methanol-gasoline ternary blends in four cylinders SI engine with port fuel injection at high content rate of ethanol-methanol blends (60 Vol.\%). Results from the above listed three studies showed that ternary fuel blends produce less NOx than gasoline. The objective of this study is to investigate the effect of gasoline-ethanol-methanol (GEM) blend on the emission characteristics $(\mathrm{CO}, \mathrm{CO} 2$, NOx and $\mathrm{HC})$ of $\mathrm{K} 3-$ VE petrol engine at variable engine speed condition. Three different fuel blends, such as E0 (gasoline), G75E21M4 (75\% gasoline, 21\% hydrous ethanol and 4\% methanol), and E25 (25\% anhydrous ethanol and 75\% gasoline) were tested. Hydrous ethanol contains 95\% ethanol and 5\% water in Vol. \%.

\section{Experimental works}

\subsection{Experiment Setup and Procedure}

In this study, the experiments were performed on 1.3 litre K3-VE engine. The specification of the engine is given in Table 1. A 200 HP DYNOMite eddy current electric absorber was used in the experiment. Eddy current absorber generates an electromagnetic field to apply rotational resistance to the spinning rotor, and hence generates heat. The water acts as a cooling medium to cool down the rotor, and this cooling water supply was connected to the eddy current electric absorber. The cooling water exiting from the absorber was sent to radiator, which then cools down the engine while flowing

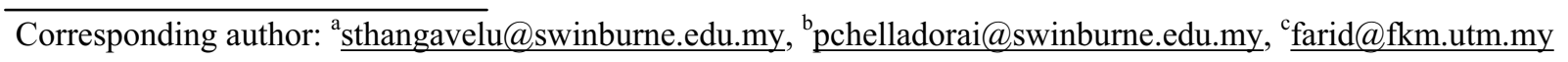


back to the water bath. There was a temperature indicator in the engine to measure exhaust gas temperature. PC with DYNO-MAX 2000 software was used to control quantity of fuel, ignition timing, injection timing, and engine speeds through different sensors connected to the engine. The engine emissions, such as $\mathrm{CO}, \mathrm{CO}_{2}, \mathrm{HC}$ and $\mathrm{NO}_{\mathrm{x}}$ were measured using calibrated flue gas emission analyzer (AVL DIGas 4000) at the engine exhaust pipe. Fig. 1 shows the schematic diagram of experimental setup. The emission behaviors of K3-VE petrol engine running in the fuels E0, G75E21M4 and E25 were evaluated. All the fuel blends were tested under variable engine speed (1000 to $6000 \mathrm{rpm}$ ) conditions at $80^{\circ}$ throttle open from horizontal. After the engine reaches the steady state condition, engine emissions were recorded using calibrated online flue gas emission analyzer.

Table 1. Engine specifications.

\begin{tabular}{|c|c|}
\hline Engine Model & K3-VE \\
\hline Engine Type & 4-Cycle, In-line 4-Cylinder \\
\hline Valve Mechanism & DVVT - DOHC \\
\hline Total Displacement $(\mathrm{cc})$ & 1298 \\
\hline Bore $\times$ Stroke $(\mathrm{mm})$ & $72 \times 79.7$ \\
\hline Compression ratio & 10 \\
\hline Maximum power $(\mathrm{kW} / \mathrm{rpm})$ & $64 / 6000$ \\
\hline Maximum torque $(\mathrm{N} \mathrm{m} / \mathrm{rpm})$ & $116 / 3200$ \\
\hline
\end{tabular}

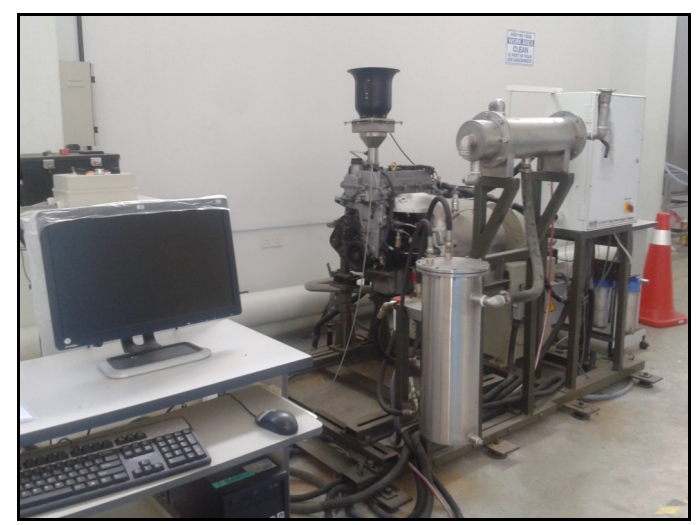

Figure 1. Schematics of experimental setup.

\section{Results and discussion}

\subsection{Carbon Monoxide}

Carbon monoxide (CO) is produced from partial oxidation of carbon containing compounds; it forms while there is no enough oxygen to produce carbon dioxide $\left(\mathrm{CO}_{2}\right)$. Fig. 2 shows the concentration of $\mathrm{CO}$ emission from the engine fueled with G75E21M4 and E25 compared to E0. A significant drop in concentration of $\mathrm{CO}$ emission was noticed for the fuel G75E21M4 and E25, which means the combustion is complete. A maximum reduction was noticed at $3000 \mathrm{rpm}$, which is $42 \%$ and $35 \%$ reduction for G75E21M4 and E25, respectively. The reduction in $\mathrm{CO}$ emission is due to less carbon content in ethanol $\left(\mathrm{C}_{2} \mathrm{H}_{5} \mathrm{OH}\right)$ and methanol $\left(\mathrm{CH}_{3} \mathrm{OH}\right)$ compared to gasoline $\left(\mathrm{C}_{8} \mathrm{H}_{18}\right)$. In addition, oxygen content in the blends increases the oxygen-to-fuel ratio in the fuel-rich regions [5]. Moreover, the relative air-fuel ratio $(\lambda)$ approaches 1 (leaning effect) for ethanol blended fuel, which provide improved and completed combustion, and thus reduce the $\mathrm{CO}$ concentration. As compared to E25 fuel, a slight drop in $\mathrm{CO}$ concentration was noticed for G75E21M4. This is due to higher oxygen content in the hydrous ethanol blends favoring conversion of $\mathrm{CO}$ produced during combustion into $\mathrm{CO}_{2}$, which is in agreement with Costa et al. [6].

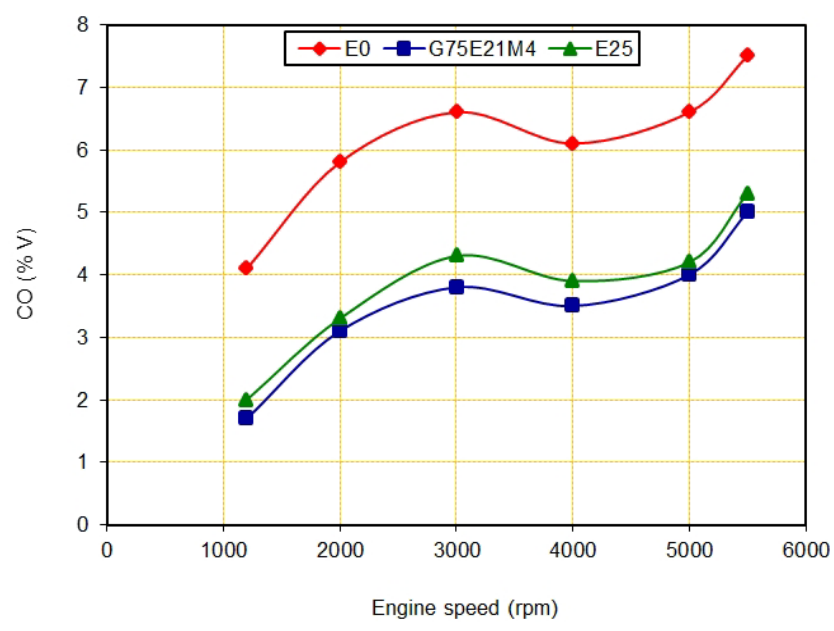

Figure 2. Carbon monoxide.

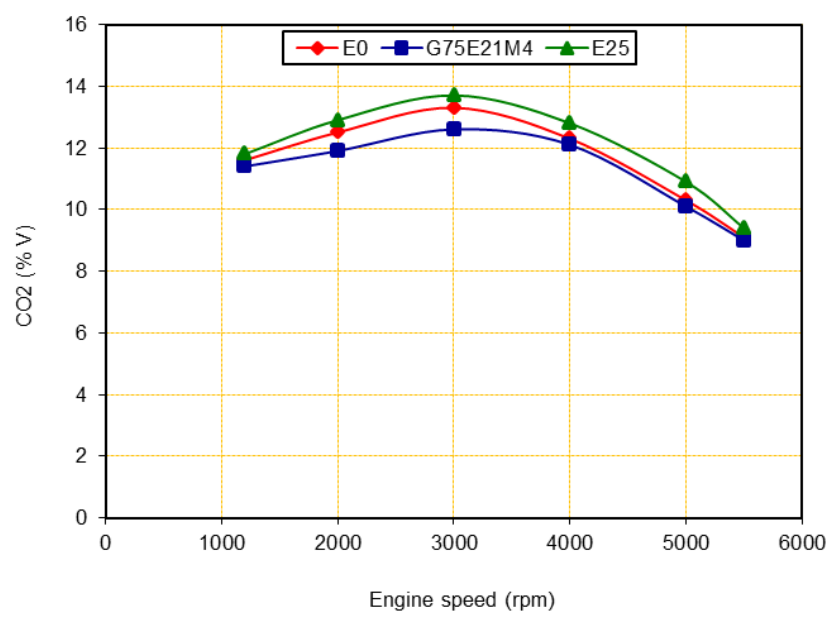

Figure 3. Carbon dioxide.

\subsection{Carbon Dioxide}

Carbon dioxide $\left(\mathrm{CO}_{2}\right)$ is produced by the complete combustion of fuel. $\mathrm{CO}_{2}$ formation is affected by the carbon-hydrogen ratio $(\mathrm{C} / \mathrm{H})$ in the fuel. Fig. 3 shows the concentration of $\mathrm{CO}_{2}$ emission from engine for the fuel blends at different speed. A slight increment in $\mathrm{CO}_{2}$ emission was noticed for E25 fuel compared to E0. A maximum of $3 \%$ increment was noticed at the engine speed $3000 \mathrm{rpm}$ for E25 fuel compared to E0. The increment in $\mathrm{CO}_{2}$ emission for E25 fuel is due to the relative air-fuel ratio ( $\lambda$ is 1.02 at $3000 \mathrm{rpm}$ ) and $\mathrm{CO}$ 
concentration [5] and moreover, improved the combustion process, as a result of oxygen content in the ethanol blends (E25). On the other hand, a significant reduction $(5.2 \%)$ in $\mathrm{CO}_{2}$ emission was noticed at 3000 rpm for G75E21M4 fuel blend compared to E0, which is probably due to lower carbon atom and $\mathrm{C} / \mathrm{H}$ ratios of the ethanol and methanol fuel, and the water content present in the fuel [7]. These emission results are comparable to previous studies. Chen et al. [7] found slight decrement in $\mathrm{CO}_{2}$ emission for hydrous ethanol E5 to $\mathrm{E} 30$ in $4 \mathrm{C}$ MPFI engine.

\subsection{Oxides of Nitrogen}

Fig. 4 shows the oxides of nitrogen $\left(\mathrm{NO}_{\mathrm{x}}\right)$ emission from the engine for different engine speed and fuel blends. A slight reduction in $\mathrm{NO}_{\mathrm{x}}$ emission was observed for ethanol fuel blends (G75E21M4 and E25) compared to gasoline (E0). A maximum of $7 \%(28 \mathrm{ppm})$ and $3 \%$ (18 ppm) reduction was observed at $5000 \mathrm{rpm}$ for G75E21M4 and E25, respectively. This is mainly due to the properties of ethanol and methanol fuel blends. The ethanol (2.7 times) and methanol (3.6 times) have higher latent heat of vaporization than that of gasoline. The mixture temperature at the end of the intake stroke decreases, and thus decreases the combustion temperature. As a result, $\mathrm{NO}_{\mathrm{x}}$ emissions decrease, which is in agreement with Celik [8]. Moreover, the reduction of $\mathrm{NO}_{\mathrm{x}}$ was dominated by the water content in the fuel mixture (G75E21M4) as reported by Chen et al. [7].

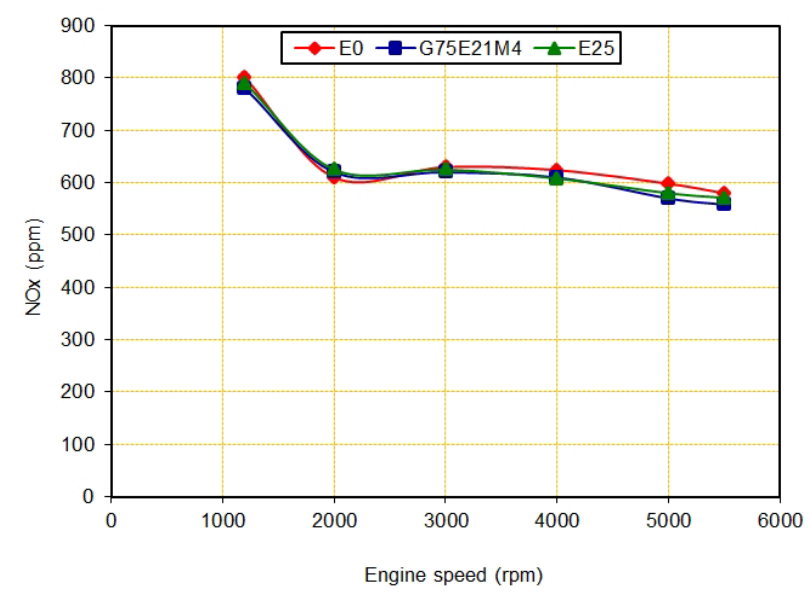

Figure 4. Oxides of nitrogen.

\subsection{Hydrocarbon}

Unburned hydrocarbon (HC) emissions are caused primarily by unburned fuel mixtures, which show improper mixing and incomplete combustion. Fig. 5 shows the unburned $\mathrm{HC}$ emissions from the engine for different engine speed and fuel blends. A significant reduction in $\mathrm{HC}$ emissions was noticed for ethanol blended fuels (G75E21M4 and E25) compared to gasoline (E0). A maximum of 15\% (37 ppm) and 18\% (45 ppm) reduction in $\mathrm{HC}$ emission was noticed at 3000 rpm for the fuel blends G75E21M4 and E25, respectively. The main reason for this reduction is due to the increase in relative air-fuel ratio $(\lambda>1)$, which is similar to that of $\mathrm{CO}$ emissions as described earlier [5]. As compared to G75E21M4 mixture, E25 shows a better reduction (3\% high) in $\mathrm{HC}$ concentration, which is due to the absence of water content in the fuel blend. As suggested by Chen et al. [7], water content in the ethanol fuel blend (G75E21M4) slightly increases the HC emission compared to anhydrous ethanol fuel (E25). Most of the previous studies found significant reduction in $\mathrm{HC}$ emission compared to gasoline. The oxygen content of the ethanol and methanol fuel blends remarkably improves the combustion efficiency. Thus, the HC emissions decreased, when ethanol or methanol blended to gasoline [9]. A significant drop in exhaust temperature for ethanol blended fuel (G75E21M4 and E25) was noticed compared to gasoline (E0). This is due to the higher latent heat of vaporization of ethanol-methanol. Moreover, the adiabatic flame temperature of ethanol and methanol are lower than gasoline, because ethanol and menthol absorb more heat from the cylinder during vaporization. In addition, heat release rate of gasoline is higher than ethanol and methanol [9]. Compared to E25 fuel, a $7.5 \%\left(30^{\circ} \mathrm{C}\right)$ drop in exhaust temperature was noticed for Eh21M4 at high speed (5000 rpm). This is due to reduced intake air temperature and its effect on combustion itself for fuel blend with hydrated ethanol.

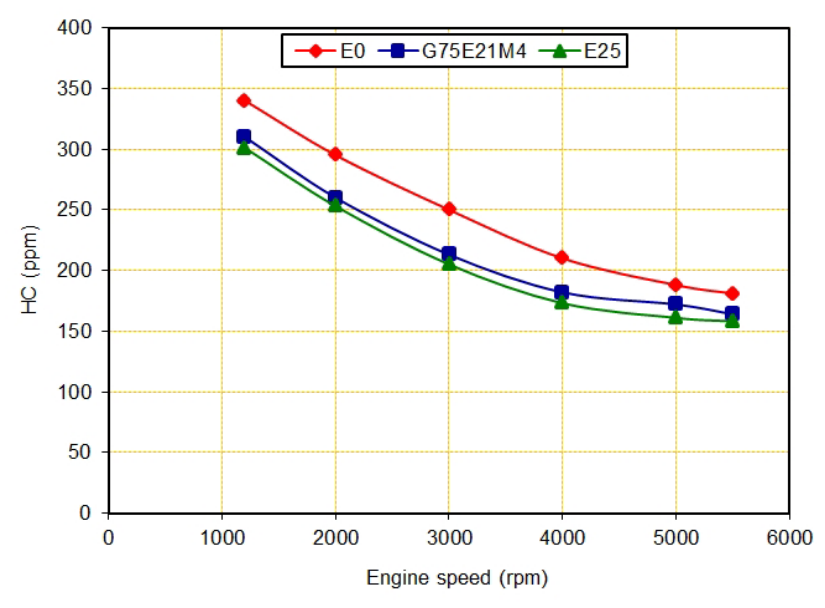

Figure 5. Hydrocarbon.

\section{Conclusion}

The effect of gasoline-ethanol-methanol (GEM) ternary blend on the emission characteristics of petrol engine (1.3-1 K3-VE spark-ignition engine) was studied. Emissions results showed a significant reduction in $\mathrm{CO}$, $\mathrm{CO}_{2}, \mathrm{NO}_{\mathrm{x}}$ and $\mathrm{HC}$ emissions by about $42 \%, 15 \%, 7 \%$ and $5.2 \%$ for G75E21M4 compared to E0, respectively. Moreover, the emission results for G75E21M4 are marginally better compared to E25 whereas; HC emission was slightly higher than E25. A significant drop in exhaust temperature for G75E21M4 and E25 was noticed compared to gasoline (E0).

\section{References}


1. S.K. Thangavelu, A.S. Ahmed, F.N. Ani, Appl. Energ. 128, 277-283 (2014)

2. J.W.G. Turner, R.J. Pearson, E. Dekker, B. Iosefa, K. Johansson, K. Bergström, Appl. Energ. 102, 72-86 (2013)

3. A. Elfasakhany, http://dx.doi.org/10.1016/j.jestch.2015.05.003

4. L. Sileghem, A. Coppens, B. Casier, J. Vancoillie, S. Verhelst, Fuel 117, 286-293 (2014)
5. G. Najafi, B. Ghobadian, T. Tavakoli, D.R. Buttsworth, T.F. Yusaf, M. Faizollahnejad, Appl. Energ. 86, 630-639 (2009)

6. R.C. Costa, J.R. Sodre, Fuel 89, 287-293 (2010).

7. R.H. Chen, L.B. Chiang, M.H. Wu, T.H. TH. Fuel 89, 604-610 (2010)

8. M.B. Celik, Appl. Therm. Eng. 28, 396-404 (2008).

9. M. Canakci, A.N. Ozsezen, E. Alptekin, M. Eyidogan, Renew. Energ. 52, 111-117 (2013) 